\title{
Occupational Burnout in Greek Teachers: A Contemporary Study in the Era of Economic Crisis
}

\author{
Michael Galanakis, Eirini Graki, Maria Dimitriadou, Ioanna Kalemaki, Eleni Kalogirou, \\ Marilena Kourbeli, Roubini Chouliara
}

Neapolis University of Pafos, Cyprus, Greece

Email: galanakismichael@hotmail.com

How to cite this paper: Galanakis, M., Graki, E., Dimitriadou, M., Kalemaki, I., Kalogirou, E., Kourbeli, M., \& Chouliara, R. (2020). Occupational Burnout in Greek Teachers: A Contemporary Study in the Era of Economic Crisis. Psychology, 11, 1170-1178.

https://doi.org/10.4236/psych.2020.118077

Received: July 17, 2020

Accepted: August 16, 2020

Published: August 19, 2020

Copyright $\odot 2020$ by author(s) and Scientific Research Publishing Inc. This work is licensed under the Creative Commons Attribution International License (CC BY 4.0).

http://creativecommons.org/licenses/by/4.0/

\begin{abstract}
Occupational Burnout is a massive occupational psychopathology syndrome that is related to many negative outcomes for the individual and the organization. One of the most prominent occupations in the burnout literature is the teaching profession. Teachers seem to be more prone to high burnout levels. The present study examined the burnout levels in Greek Teachers and tried to answer whether the phenomenon is affected by gender, age, marital status, number of children and years of service. Results show that even though burnout is not gender related, it is affected by the working conditions and other demographic variables such as marital status. Further implications for research and practice are discussed.
\end{abstract}

\section{Keywords}

Burnout, Stress, Teachers, Greece, Working Conditions, Economic Crisis

\section{Introduction}

The purpose of this paper is to investigate the occupational burnout of primary school teachers and the factors that contribute to this phenomenon. This paper is triggered by the difficulty that teachers sometimes face in their interpersonal relationships at school. The educational reality especially in Greece is harsh with many changes in the legislation, heavy program and various difficulties stemming from students' and parents' demands.

\subsection{Definitions of Occupational Burnout}

"Occupational burnout" is the term we use for the lack of interest, motivation and 
disposition due to working conditions. According to Edelwich and Brodsky (1980), occupational burnout refers to "the gradual loss of idealism, energy, purpose and interest as a result of working conditions". In the beginning, the individual is excited and when occupational burnout occurs, he or she experiences stagnation, cancellation, denial and is driven to indifference (Skaalvik \& Skaalvik, 2009).

Many definitions have been given of the phenomenon of burnout, and they all converge that emotional fatigue and exhaustion negatively affect one's performance, reducing his/her performance (Schaufeli \& Buunk, 1996).

According to Freudenberger (1974), occupational burnout is considered to be the improper performance at work due to emotional exhaustion because of excessive demands (Freudenberger, 1975). Pines (1981) argues that the life of an individual is meaningful only when doing useful things. So, if he or she fails at conducting his/her job, it results in occupational burnout. The most common definition is Maslach's (1982), whose name is inextricably linked to occupational burnout, as it has developed the tool for measuring occupational burnout. According to Maslach, the lack of interest in people who co-exist in the same work environment is due to emotional exhaustion, resulting in a lack of interest and respect for the colleague or client (McGee-Cooper, Trammell, \& Lau, 1990).

\subsection{Factors That Contribute to the Appearance of Phenomenon}

In the early 1980s, researchers linked the causes of teacher burnout syndrome to demographic factors such as age, gender, marital status, prior employment, and so on. At the end of the same decade, research focused on work-related factors (environment, administration, workload, etc.) (Kollia, 2019). Concerning this particular syndrome, recent research has focused more on excessive workload (Chang, 2009).

The reasons for the onset of occupational burnout relate to: 1) demographics; 2) working conditions; 3 ) individual factors (personal characteristics); and 4) the interaction of the above parameters. Some of the factors of the syndrome are the job role that the person assumes (contact with other people, conflicts, etc.), as well as the specific characteristics of his/her workplace (pay, climate, infrastructure, etc.), as well as the demographic or personal characteristics of each individual (Kollia, 2019).

Factors considered by researchers to be contributing to occupational burnout syndrome, some more or less, are categorised into 1) demographic, 2) occupational, and 3) individual. Chang (2009) has classified them into three main categories based on research done to identify factors contributing to teacher burnout: Individual factors, Organisational factors and Transactional factors.

\subsection{Occupational Burnout Models}

One theory for interpreting teacher burnout is Maslach's and Jackson's (1982), which contains three stages. The first stage is about "emotional exhaustion" where the person does not have the same energy level he or she had at the beginning of his/her career and his/her motivations and expectations are not re- 
newed but his/her demands are increased so he/she considers that he/she does not impart any further knowledge to his students.

Then in the second stage of "Depersonalisation" they have negative feelings for their students and behave rudely and inappropriately towards them. When the teacher goes through the stage of "lack of personal achievement", he or she now experiences feelings of frustration and failure about the goals he or she has set in the beginning and feels the need to quit his/her job (Chrysouli, 2017).

Another important theory regarding occupational burnout is Ederlwich and Brodsky's, where the teacher initially feels excited about their new beginning and sets high goals, and in the event of failure, s/he becomes frustrated. This results in blaming external factors for his/her problems and not doing an internal search or revision of his/her goals. This is why he or she is now in a deadlock and working only to make a living (Kollia, 2019).

To measure occupational burnout, Shirom-Melamed Burnout Measure was created and has been influenced by the Shirom-Melamed model, where occupational burnout was initially thought to be the physical fatigue of the employee, then emotional exhaustion and finally mental fatigue (Daniilidou, 2013).

\subsection{Main Research Findings}

Teachers, exercising a predominantly humanitarian profession, are subject to more stressful conditions than other professions and are often led to occupational burnout. Factors that aggravate the tendency of the syndrome are workload, large scope of responsibility, minimal positive feedback and daily stressful stimuli in the school environment (Antoniou \& Dalla, 2010).

Research on the demographic variable of gender on the impact of occupational burnout has yielded ambiguous results, thus disputing the dominant notion that women are more prone and vulnerable to occupational burnout (Purranova \& Muros, 2010). Equally blurry is the landscape in the relationship between years of service and the burnout syndrome. The research findings emphasise the need for further investigation into the relationship between gender, teaching experience and occupational burnout.

\subsection{Research Questions}

Based on the above bibliographic review of occupational burnout, two key questions emerge that will address the research of this work.

1) Are there gender differences in occupational burnout?

2) Do years of service affect teachers' levels of burnout?

\section{Method}

\subsection{Sample}

The purpose of this study was to determine whether years of service play a role in occupational burnout and whether the gender of teachers matters. Quantitative research was chosen to study the relationship of variables. 
Our sample was primary school teachers from different parts of Greece. The survey took place in the 2019-2020 school period and lasted three weeks. The desired sample size was 120 teachers for reasons of statistical power and external validity.

\subsection{Research Tools}

The data collection tool we used was the questionnaire. After reviewing the literature, it was decided to use the Occupational Syndrome Questionnaire (Maslach, Jackson, \& Schwab, 1996).

Demographics and information on the marital status and educational level of the participants were requested first. The questionnaire structure consists of six scales, which refer to the frequency of experiencing the symptoms $(0=$ never, 1 = several times a year, $2=$ once a month, $3=$ several times a month, $4=$ once a week, $5=$ several times per week, $6=$ every day).

The questionnaire is an easy-to-use, user-friendly, and researcher-friendly research tool (Masclach et al. 1996). The OSQ had satisfactory psychometric qualities in our sample (Cronbach $\alpha=0.82$ ).

\subsection{Procedure}

This research was designed as an action research. Prior to data gathering informed consent was given from all schools that participated in the study. 4 Schools were chosen randomly and with the provision to select students from different parts of the country. All sample participants completed the questionnaires anonymously via Google forms. The data gathering procedure lasted 3 weeks. No problems arose during questionnaire completion. All targeted teachers agreed to participate in the study, thus the rejection rate was $0 \%$.

\subsection{Ethics and Code of Conduct}

Before completing the questionnaire with the demographics form it was clearly stated to the sample that they have the right not to respond to something they do not want, or even to withdraw from the research, their anonymity will be guaranteed and there will be confidentiality during and after the research,

- The researching staff will make sure that the participants do not feel uncomfortable during the selection of data and

- Participants will, if necessary, be advised by researchers on any issues that may arise during the research.

\subsection{Statistical Analysis}

Our research is quantitative; we used the SPSS statistical package V. 22 to analyse the collection data. We focused on these specific variables: teacher burnout with years of service, gender, and whether there is a correlation between them.

\section{Results}

In Table 1, we observe that our total sample was 125 individuals. Of this sample, 
$78 \%$ were female and $22 \%$ male, the age range of our sample ranged from younger than 30 to older than 60 , with the highest percentage ranging between 41 and 50 years. Years of service were from 0 years up to more than 30 years, with the highest participation being those from 0 to 5 years. The largest percentage of the sample was married (66\%), compared to single (34\%) and had no children up to 4 , with most having 0 children.

Next, in Table 2, we note that most people in the sample find that they work hard, while fewer find it tiring to work with other people. Most teachers find that they create a pleasant atmosphere in their teaching environment and fewer face emotional burdens calmly. Finally, most educators feel tough with other people, while fewer say they are not interested in interacting with others.

Next we estimated cross tabulations between the burnout factors and demographic variables, namely gender, age group, years of service, marital status and number of children. The distribution of these variables was normal and eligible for carrying out the analysis.

Table 1. Sample demographics.

\begin{tabular}{|c|c|}
\hline Total sample & $\mathrm{N}=125$ \\
\hline \multicolumn{2}{|l|}{ Gender - n (\%) } \\
\hline Male & $27(22 \%)$ \\
\hline Female & $98(78 \%)$ \\
\hline \multicolumn{2}{|l|}{ Age - n (\%) } \\
\hline$<30$ & $26(21 \%)$ \\
\hline $31-40$ & $35(28 \%)$ \\
\hline $41-50$ & $36(29 \%)$ \\
\hline $51-60$ & $27(22 \%)$ \\
\hline$>60$ & $1(1 \%)$ \\
\hline \multicolumn{2}{|l|}{ Years of service } \\
\hline $0-5$ & $52(42 \%)$ \\
\hline $6-10$ & $23(18 \%)$ \\
\hline $11-20$ & $35(28 \%)$ \\
\hline $21-30$ & $12(10 \%)$ \\
\hline$>30$ & $3(2 \%)$ \\
\hline \multicolumn{2}{|l|}{ Civil status } \\
\hline Single & $42(34 \%)$ \\
\hline Married & $82(66 \%)$ \\
\hline \multicolumn{2}{|l|}{ Children } \\
\hline 0 & $52(42 \%)$ \\
\hline 1 & $23(18 \%)$ \\
\hline 2 & $35(28 \%)$ \\
\hline 3 & $12(10 \%)$ \\
\hline 4 & $3(2 \%)$ \\
\hline
\end{tabular}


Table 2. Mean and median indexes on the 3 subscales of the occupational burnout questionnaire.

\begin{tabular}{|c|c|c|}
\hline & Median (IQR) & Mean $(95 \%$ CI $)$ \\
\hline Emotional exhaustion score & $13(8-18.5)$ & $14.66(13.07-16.26)$ \\
\hline 6. mentally exhausted & $1(1-3)$ & $2.03(1.75-2.31)$ \\
\hline 7. I feel empty & $0(0-1)$ & $0.92(0.67-1.17)$ \\
\hline 8. I feel tired & $1(0-3)$ & $1.55(1.27-1.84)$ \\
\hline 13. exhausted & $1(1-3)$ & $1.84(1.55-2.13)$ \\
\hline 11. tiring working with people & $1(0-1)$ & $0.87(0.67-1.07)$ \\
\hline 18. I feel disappointed & $1(0-2)$ & $1.04(0.82-1.26)$ \\
\hline 19. I work hard & $4(2.5-5)$ & $3.74(3.41-4.08)$ \\
\hline 21. Stress from contact with people & $1(0-2)$ & $1.15(0.90-1.40)$ \\
\hline 25. at the limits of my strength & $1(0-2)$ & $1.51(1.24-1.78)$ \\
\hline Personal achievements score & $41(35-44)$ & \\
\hline 9. I can easily understand & $5(5-6)$ & $5.16(4.97-5.35)$ \\
\hline 12. I deal with problems effectively & $5(4-6)$ & $4.62(4.36-4.87)$ \\
\hline 14. I have a positive influence & $5(5-6)$ & $5.02(4.81-5.24)$ \\
\hline 17. I feel full & $5(4-6)$ & $4.75(4.51-4.99)$ \\
\hline 22. cosy atmosphere & $6(5-6)$ & $5.34(5.17-5.52)$ \\
\hline 23. rejuvenated & $5(5-6)$ & $5.18(4.98-5.38)$ \\
\hline 24. I have accomplished remarkable things & $5(4-6)$ & $4.65(4.41-4.89)$ \\
\hline 26. I deal with emotional burdens calmly & $5(3-6)$ & $4.19(3.89-4.50)$ \\
\hline Depersonalisation score & $2(0-4)$ & \\
\hline 10. I act impersonally & $0(0-1)$ & $0.64(0.43-0.85)$ \\
\hline 15. I am tough on people & $0(0-1)$ & $0.86(0.60-1.13)$ \\
\hline 16. Work makes me tough & $0(0-1)$ & $0.70(0.45-0.94)$ \\
\hline 20. I do not care & $0(0-0)$ & $0.34(0.19-0.48)$ \\
\hline 27. They blame me for their problems & $0(0-1)$ & $0.48(0.33-0.63)$ \\
\hline
\end{tabular}

Table 3 presents the results of our study. Therefore, according to the results of our measurements, teachers, between 31 and 40, are those who adopt a more impersonal profile and are distanced. Teachers whose years of service range from 6 to 10 years, experience the greatest occupational burnout and deprivation. Finally, married people are more satisfied with their educational work. Nevertheless, for one of the main variables of our design, gender, no statistical significant differences were observed.

\section{Discussion}

The purpose of this paper was to identify the factors that contribute to teachers' burnout and influence their career path. The survey involved 125 primary 
Table 3. Cross tabulation of the 3 occupational burnout factors with demographic variables.

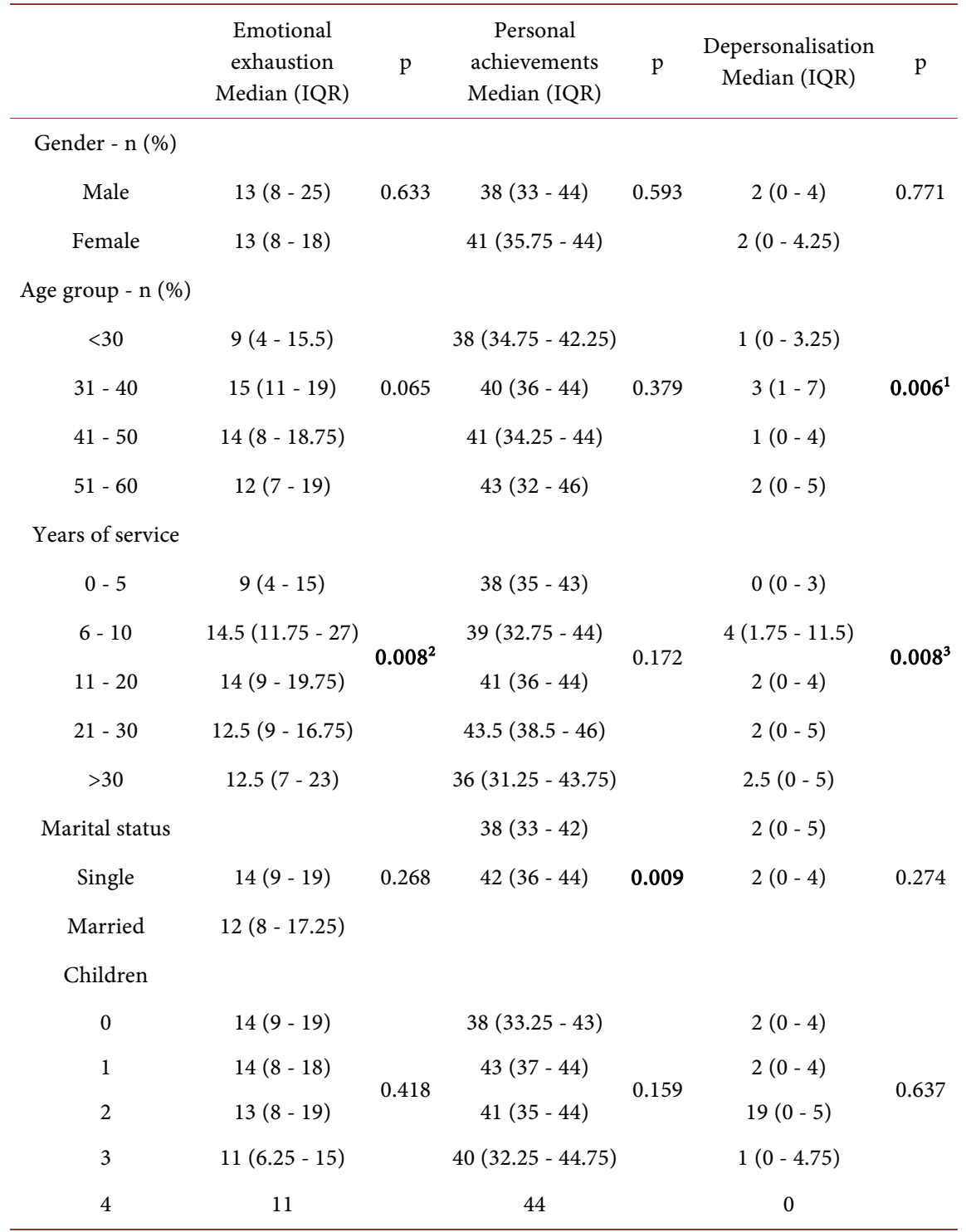

Age $>60$ is missing because there is only 1 person. Bold are statistically significant $(\mathrm{p}<0.05)$. ${ }^{1}$ Statistically significant difference between groups $<30$ and $31-40$ (Bonferroni corrected $p=0.013$ ) and between groups $31-40$ and $41-50$ (Bonferroni corrected $\mathrm{p}=0.035$ ); ${ }^{2}$ Statistically significant difference between groups 0 - 5 and $11-20$, and between groups $0-5$ (Bonferroni corrected $p=0.02$ ) and $6-10$ (Bonferroni corrected $\mathrm{p}=0.009$ ); ${ }^{3}$ Statistically significant difference between groups $0-5$ and $6-10$ (Bonferroni corrected $\mathrm{p}=0.002$ ).

education teachers from different regions of Greece.

According to the results of our study, there are no differences between the genders, which contradict the research of Purranova \& Muros (2010) who, after 183 studies, concluded that women were more likely to report occupational burnout in comparison to men.

Chang (2009), in a survey conducted among English teachers in England, had the same results as our own survey regarding gender, since no significant differences were found between men and women. 
Greater occupational burnout and depersonalisation occurred to teachers who had 6 to 10 years of service, which we did not expect, as we believe that the teacher is at the beginning of his/her academic career, which leads to more willingness for work. One explanation for this finding may be that burnout stems from expectations and the younger the teacher the more the expectations, dreams, hopes for bringing a good result in the classroom. We believed that occupation burnout would be for teachers with most years of service, who would have had a stronger element of depersonalisation. Also, married people feel more satisfied with their educational work. Kollia's (2019) survey of 171 teachers in Attica showed that male teachers were more impersonal than women and that married teachers presented more fatigue, which contradicts our research.

\section{Conclusion}

The conclusions of our research are that teachers between the ages of 30 and 40 are experiencing the greatest occupational burnout, with relatively few years of teaching. Depersonalisation is statistically significant. The gender and number of children of teachers do not affect their occupational burnout.

In order to avoid or mitigate burnout, it would be wise to have sufficient time to prepare the educational process, have classes with fewer students for more efficient teaching, fewer teaching hours, better financial gain.

In the next phase, we propose that it would be useful to consider occupation burnout among permanent and substitute teachers.

\section{Conflicts of Interest}

The authors declare no conflicts of interest regarding the publication of this paper.

\section{References}

Antoniou, A. S., \& Dalla, M. (2010). Occupational Burnout and Satisfaction from the Profession of Greek Teachers (of Special and General Education) and Secondary Education Teachers: Comparative Study. In Ch. Karakioulafi \& M. Spyridaki (Ed.), Work \& Society (pp. 365-399). Athens: Dionikos.

Chang, M. L. (2009). An Appraisal Perspective of Teacher Burnout: Examining the Emotional Work of Teachers. Educatioanl Psychology Review, 21, 193-218. https://doi.org/10.1007/s10648-009-9106-y

Chrysouli, F. (2017). Occupational Stress \& Teacher Burnout Syndrome in Primary \& Secondary Education: The Case of Schools of the Kallikratis Municipality of Vari-Voula Vouliagmeni. Athens: Thesis at Harokopio University.

Daniilidou, A. (2013). The Study of Primary Education Teacher Occupational Burnout with Three Alternative Models: The Maslach Model, the Pines Model and the Copenhagen Model. Thessaloniki: Thesis at the University of Macedonia.

Freudenberger, H. J. (1974). The Staff Burnout Syndrome in Alternative Institutions Psychotherapy. Theory Research and Practice, 12, 73-82.

https://doi.org/10.1037/h0086411

Kollia, E. (2019). Work-Related Stress and Job Burnout of Primary School Teachers in 
Attica during the Years of Financial Crisis: Investigating Teachers' Views. Patras: Thesis at the Hellenic Open University.

Masclach, C., Jackson, S. E., Leiter, M. P., Schaufeli, W. B., \& Schwab, R. L. (1996). Maslach Burnout Inventory Manual (pp. 191-218). Menlo Park. CA: Mind Garden.

Maslach, C. (1982). Burnout: The Cost of Caring. Englewood Cliffs, NJ: Prentice Hall.

Maslach, C., \& Jackson, S. E. (1982). Burnout in Health Professions: A Social Psychological Analysis. Social Psychology of Health and Illness, 227, 251.

Maslach, C., Jackson, S. E., \& Schwab, R. L. (1996). Maslach Burnout Inventory Educators Survey (MBI-ES). In C. Maslach, S. E. Jackson, \& M. P. Leiter (Eds.), MBI Manual (3rd ed.). Palo Alto, CA: Consulting Psychologists Press.

McGee-Cooper, A., Trammell, D., \& Lau (1990). You Don't Have to Go Home from Work Exhausted: The Energy Engineering Approach. Dallas, Bowen \& Rogers.

Purranova, R. K., \& Muros, J. P. (2010). Gender Differences in Burnout: A Meta-Analysis. Journal of Vocational Behavior, 77, 168-185. https://doi.org/10.1016/j.jvb.2010.04.006

Schaufeli, W. B., \& Buunk, B. P. (1996). Professional Burnout. Handbook of Work and Health Psychology Issue, 311-346.

Skaalvik, E. M., \& Skaalvik, S. (2009). Does School Context Matter? Relations with Teacher Burnout and Job Satisfaction. Teaching and Teacher Education, 25, 518-524. https://doi.org/10.1016/j.tate.2008.12.006 